\title{
Obstructive Airway Disease: Rational, Evidence-Based Bronchodilator Therapy
}

The Berlinski and Pennington study ${ }^{1}$ in the September issue of RESPIRATORY CARE is of considerable interest, not only because it is good science, but also because it invites important clinical conclusions. The authors found that the previously held notion (see package inserts for hydrofluoroalkane Ventolin, Proventil, and Proair) that it is necessary to wait $60 \mathrm{~s}$ between albuterol puffs was clinically irrelevant, although probably statistically significant. Indeed, $15 \mathrm{~s}$ rather than $1 \mathrm{~min}$ between puffs is sufficient to achieve clinically comparable doses (approximately $15 \%$ dose reduction vs 1-min delay between puffs) delivered at the mouth. Additionally, although there were modest differences in the dose/puff between the brands of albuterol, there are, for the most part, similar particle dimensions with either the 15- or 60-s duration between puffs (mass median aerodynamic diameter) and fine particle mass (mass median aerodynamic diameter $<5$ and $1-3 \mu \mathrm{m}$ ). Thus, it is evident that delaying repeated metered-dose inhaler (MDI) puffs for $>20 \mathrm{~s}$ (including shaking the canister) is not necessary and may result in considerable delay in administering a rescue dose that may require $10-12$ puffs $(1,000-$ $1,200 \mu \mathrm{g}$ from the MDI) of albuterol in severe acute asthma exacerbations, equivalent to $2,500 \mu \mathrm{g}$ from a small-volume nebulizer. ${ }^{2,3}$ Thus, the rescue medications can be delivered within 3-4 min by means of a valved holding chamber (VHC) in contrast to the 15-20 min required for a clinically equivalent dose administered via a small-volume nebulizer. The present study also adds strength to a previous clinical study in children showing that only 2-3 tidal breaths are necessary to empty a VHC used with Ventolin, ${ }^{4}$ thus adding only an additional few seconds to complete the rescue therapy.

A major conclusion of their study was a saving of respiratory therapist/nurse time (increased efficiency). Additionally, the much shorter time required for improve-

\footnotetext{
Dr Newhouse has disclosed relationships with InspiRx Pharmaceuticals and Nostrum Pharmaceuticals. Dr Amirav has disclosed a relationship with InspiRx Pharmaceuticals. Both authors have patent rights for inhalation devices for infants and children.
}

Correspondence: Michael T Newhouse MD, 436 Queen St. S., Hamilton, Ontario L8P 3T9, Canada. E-mail: casanova1935@adlan.com.

DOI: $10.4187 /$ respcare. 05786 ment to begin and peak would probably make it possible for physicians to care for more patients in the emergency department. We would suggest that there would be a considerable similar saving of the caregiver's time at home

See the Original Study on Page 1123

(for maintenance therapy with the MDI + VHC approximately $2-3 \mathrm{~min}$ vs $30 \mathrm{~min}$ for small-volume nebulizer if we, appropriately, include cleaning, assembling, and loading the small-volume nebulizer) as well as the much greater convenience and lower cost per dose of medication with the MDI + VHC for equivalent benefit. This would be of particular importance in cystic fibrosis, where aerosol therapies may take $2 \mathrm{~h}$ daily. By using an MDI + VHC instead of a small-volume nebulizer for bronchodilator and corticosteroid therapy, the treatment time could be reduced by almost $1 \mathrm{~h}$. Furthermore, there is the rare but serious bronchoconstrictor effect of the preservative benzalkonium chloride added to some albuterol nebulizer solutions. ${ }^{5}$ Taken together, it is hard to avoid the conclusion that the use of small-volume nebulizers for administration of inhaled bronchodilators and corticosteroids should be considered obsolete and an imposition on patients and caregivers in hospitals and at home both for maintenance therapy and for exacerbations. Unfortunately, the Food and Drug Administration's guidance for MDI use makes MDI costs difficult for the hospital pharmacy budget to absorb. However, the university hospital in Gainesville, Florida, has issued a guidance that safely circumvents this problem (Dr L Hendeles, personal communication). By extrapolation, there would predictably be a reduction in the overall cost of therapy, since bronchodilator therapy with the pressurized MDI and VHC in the emergency department has been shown to be much faster than small-volume nebulizer therapy with the resulting more rapid recovery of the patient, who can presumably be discharged home sooner.

Ultimately, this study again begs the question of why small-volume nebulizers continue to be used in preference to MDIs + VHCs (by a ratio of approximately 10:1) in the United States but rarely in Canada, Australia, New Zealand, and Europe for managing asthma, COPD, and other conditions characterized by reversible airway obstruction 


\section{EDITORIALS}

when the evidence indicates (and various national and international guidelines suggest) that virtually all patients from infants to the elderly can be equally well-treated or better-treated with MDI-generated bronchodilators and corticosteroids and VHCs.

There has been, for many years, accumulating and convincing physiologic, pharmacologic, and clinical evidence that hydrofluoroalkane pressurized MDIs mated to evidence-based VHCs are equivalent or better aerosol delivery systems, particularly for small children, due to their generally smaller aerosols and greatly improved, childfriendly, and low-dead-space masks. ${ }^{6-8}$ Additionally, MDIs are less expensive per dose (and, with the soonto-be-introduced generic MDIs, will doubtless be even less expensive) and provide much more rapid and convenient therapy than small-volume nebulizers. These factors, in turn, make adherence more likely. Because small-volume nebulizers, in general, produce much larger particles than MDIs, the use of a small-volume nebulizer is associated with greater deposition in the upper-respiratory tract and larger lower-respiratory tract airways, resulting in reduced benefit and increased systemic absorption. This also has implications for adverse effects, such as tachycardia, tachyarrhythmias, and anxiety. With newer MDI formulations having a mass median aerodynamic diameter of about 1-2 $\mu \mathrm{m}$ (so-called ultrafine particles), it has been shown with inhaled corticosteroids 8 that for chronic management, for example, the dose can be reduced to one-half the dose required previously with similar benefit, indicating greater therapeutic efficacy and lower cost.

Finally, since adherence continues to be a major problem, exacerbations causing a visit to the emergency department provide an unequalled opportunity to initiate instruction of patients and caregivers in the use of inhaled prophylactic corticosteroid therapy with MDIs and VHCs when they are most teachable. This could minimize the likelihood of future exacerbations and instruct them in the use of the VHC or VHC with an appropriate mask in small children. ${ }^{9}$ Ideally and most cost-effectively, patients should be sent home with the relatively inexpensive VHC and aerosol devices that they need and with written instructions to minimize the likelihood that they will require early readmission. This message should appeal to the insurance industry in the United States (or to the taxpayer/health ministry in national health-care systems), who are certainly aware that the cost of asthma exacerbations requiring hospitalization far exceeds the cost of providing patients with the intellectual and physical tools to keep them well and out of hospital!

Michael T Newhouse MD McMaster University Hamilton, Ontario, Canada

Israel Amirav MD

Department of Pediatrics University of Alberta Edmonton, Alberta, Canada

\section{REFERENCES}

1. Berlinski A, Pennington D. Effect of interval between actuations of albuterol hydrofluoralkane pressurized metered dose inhalers on their aerosol characteristics. Respir Care 2017;62(9):1123-1130.

2. Mandelberg A, Chen E, Noviski N, Priel IE. Nebulized wet treatment in emergency department-is it essential? Comparison with large spacer device for metered-dose inhaler. Chest 1997;112(6):1501-1505.

3. Idris AH, McDermott MF, Raucci JC, Morrabel A, McGorray S, Hendeles L. Emergency department treatment of severe asthma: metered-dose inhaler plus holding chamber is equivalent in effectiveness to nebulizer. Chest 1993;103(3):665-672.

4. Schultz A, Le Souëf TJ, Venter A, Zhang G, Devadason SG, Le Souëf PN. Aerosol inhalation from spacers and valved holding chambers requires few tidal breaths for children. Pediatrics 2010;126(6):e1493e1498.

5. George M, Joshi SV, Concepcion E, Lee H. Paradoxical bronchospasm from benzalkonium chloride (BAC) preservative in albuterol nebulizer solution in a patient with acute severe asthma: a case report and review of the literature. Respir Med Case Rep 2017;21:39-41.

6. Pollock M, Sinha IP, Hartling L, Rowe BH, Schreiber S, Fernandes RM. Inhaled short-acting bronchodilators for managing emergency childhood asthma: an overview of reviews. Allergy 2017;72(2):183-200.

7. Amirav I, Luder AS, Halamish A, Marzuk C, Daitzchman M, Newhouse MT. Computerized dead-space volume measurement of face masks applied to simulated faces. Respir Care 2015;60(9):1247-1251.

8. van Aalderen WM, Grigg J, Guilbert TW, Roche N, Israel E, Martin RJ, et al. Small-particle inhaled corticosteroid as first-line or step-up controller therapy in childhood asthma. J Allergy Clin Immunol Pract 2015;3(5):721-731.

9. Krishnan, JA, Martin, MA, Lohff C, Mosnaim GS, Margellos-Anast $\mathrm{H}$, DeLisa JA, et al. Design of a pragmatic trial in minority children presenting to the emergency department with uncontrolled asthma: the CHICAGO plan. Contemp Clin Trials 2017;57:10-22. 